\title{
Aerosol mixing state, hygroscopic growth and cloud activation efficiency during MIRAGE 2006
}

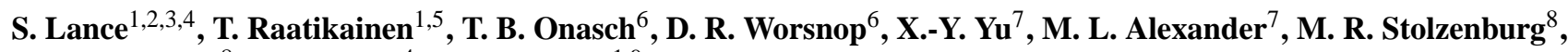 \\ P. H. McMurry ${ }^{8}$, J. N. Smith ${ }^{4}$, and A. Nenes ${ }^{1,9}$ \\ ${ }^{1}$ School of Earth and Atmospheric Sciences, Georgia Institute of Technology, Atlanta, GA, USA \\ ${ }^{2}$ Earth System Research Laboratory, National Oceanic and Atmospheric Administration, Boulder, CO, USA \\ ${ }^{3}$ Cooperative Institute for Research in Environmental Sciences, University of Colorado, Boulder, CO, USA \\ ${ }^{4}$ Atmospheric Chemistry Division, National Center for Atmospheric Research, Boulder, CO, USA \\ ${ }^{5}$ Finnish Meteorological Institute, Helsinki, Finland \\ ${ }^{6}$ Aerodyne Research Inc., Billerica, MA, USA \\ ${ }^{7}$ Pacific Northwest National Laboratory, Richland, WA, USA \\ ${ }^{8}$ Department of Mechanical Engineering, University of Minnesota, Minneapolis, MN, USA \\ ${ }^{9}$ School of Chemical and Biomolecular Engineering, Georgia Institute of Technology, Atlanta, GA, USA
}

Correspondence to: A. Nenes (athanasios.nenes@gatech.edu)

Received: 14 May 2012 - Published in Atmos. Chem. Phys. Discuss.: 25 June 2012

Revised: 18 January 2013 - Accepted: 7 April 2013 - Published: 15 May 2013

\begin{abstract}
Observations of aerosol hygroscopic growth and CCN activation spectra for submicron particles are reported for the T1 ground site outside of Mexico City during the MIRAGE 2006 campaign. $\kappa$-Köhler theory is used to evaluate the characteristic hygroscopicity parameter, $\kappa^{*}$, for the $\mathrm{CCN}$ active aerosol population using both size-resolved HTMDA and size-resolved CCNc measurements. Organic mass fractions $\left(f_{\text {org }}\right)$ are evaluated from size-resolved aerosol mass spectrometer (AMS) measurements, from which predictions of the hygroscopicity parameter are compared against $\kappa^{*}$.

Strong diurnal changes in aerosol water uptake parameters and aerosol composition are observed. We find that new particle formation (NPF) events are correlated with an increased $\kappa^{*}$ and $\mathrm{CCN}$-active fraction during the daytime, with greater impact on smaller particles. During NPF events, the number concentration of $40 \mathrm{~nm}$ particles acting as $\mathrm{CCN}$ at $0.51 \% \pm 0.06 \%$ supersaturation can surpass by more than a factor of two the corresponding concentrations of $100 \mathrm{~nm}$ particles. We also find that at 06:00-08:00 LT throughout the campaign, fresh traffic emissions result in substantial changes to the chemical distribution of the aerosol, with on average $65 \%$ externally mixed fraction for $40 \mathrm{~nm}$ parti-
\end{abstract}

cles and $30 \%$ externally mixed fraction for $100 \mathrm{~nm}$ particles, whereas at midday nearly all particles of both sizes can be described as "internally mixed".

Average activation spectra and growth factor distributions are analyzed for different time periods characterizing the daytime (with and without NPF events), the early morning "rush hour" and the entire campaign. We show that $\kappa^{*}$ derived from $\mathrm{CCNc}$ measurements decreases as a function of size during all time periods, while the $\mathrm{CCN}$-active fraction increases as a function of size. Size-resolved AMS measurements do not predict the observed trend for $\kappa^{*}$ versus particle size, which can be attributed to unresolved mixing state and the presence of refractory material not measured by the AMS. Measured $\kappa^{*}$ typically ranges from 0.2 to 0.35 , and organics typically make up $60-85 \%$ of the aerosol mass in the size range studied. We show that $\kappa_{\mathrm{AMS}}$ is able to describe $\mathrm{CCN}$ concentrations reasonably well, provided mixing-state information is available, especially at the highest CCN concentrations. This is consistent with other CCN studies carried out in urban environments, and is partly due to the fact that the highest $\mathrm{CCN}$ concentrations occur during the daytime when the aerosol is internally mixed. During the 
early morning rush hour, however, failing to account for the aerosol mixing state results in systematic overestimation of $\mathrm{CCN}$ concentrations by as much as $50-100 \%$ on average.

\section{Introduction}

The greater Mexico City area is home to $\sim 20$ million people, making it one of the most populous metropolitan areas in the world. The city is situated on a dry lake bed at an altitude of $\sim 2200 \mathrm{~m}$ and is surrounded by mountains, resulting in a unique environment with dense atmospheric pollutants trapped at high altitude, where rapid photochemical oxidation can take place. Understanding the sources and evolution of particulate matter in Mexico City are two important objectives for the international investigation within and downwind of Mexico City called MILAGRO (Megacity Initiative: Local and Global Research Observations, http://www.ucar.edu/ communications/quarterly/spring06/milagro.jsp). A subset of this study, called MIRAGE (Megacities Impacts on Regional and Global Environments), included measurements at several ground-based sites (Fast et al., 2007; Molina et al., 2010) over the month of March 2006.

The impact of aerosols on climate, visibility and human health depends on the degree to which particles swell in humid environments and the efficiency with which particles act as cloud condensation nuclei (CCN). The measurements presented here focus on the water uptake properties of ambient aerosol outside of Mexico City at the University of Tecamac (T1) ground site from 16-31 March 2006. Measurements under both subsaturated (relative humidity, $\mathrm{RH}<100 \%$ ) and supersaturated $(\mathrm{RH}>100 \%)$ conditions were obtained, from which the evolution of the aerosol mixing state is analyzed in detail. In the following analysis, we discuss the dominant processes impacting the aerosol water uptake properties (e.g., new particle formation events, primary emissions and aging of the aerosol).

\section{Methods}

\subsection{Measurements and instrumentation}

Ambient air was sampled continuously through an inlet above the roof of a portable air-conditioned laboratory operated by the National Center for Atmospheric Research. An inline impactor located inside the laboratory removed particles greater than $1 \mu \mathrm{m}$ and was cleaned twice each day due to the heavy dust load. The sample line was split immediately after the impactor between two independent systems to measure size-resolved $\mathrm{CCN}$ activation spectra (the fraction of particles that form cloud droplets for a given dry particle size and water vapor supersaturation) and aerosol hygroscopicity (the equilibrium uptake of water by particles exposed to $\mathrm{RH}<100 \%$ ). Particles with $40-100 \mathrm{~nm}$ diame- ter were targeted because the threshold activation diameter (corresponding to the critical supersaturation where $50 \%$ of $\mathrm{CCN}$-active particles are activated) often falls within this size range for typical cloud supersaturations (Andreae and Rosenfeld, 2008).

To obtain size-resolved CCN activation spectra, a similar experimental setup to Cerully et al. (2011) was used. The sampled aerosol was electrostatically classified with a differential mobility analyzer (nanoDMA, TSI 3085) (Chen et al., 1998) using a 210-Po neutralizer. Activation spectra were obtained for four classified dry particle sizes (nominally $40,60,80$ and $100 \mathrm{~nm}): 41.7 \pm 0.48 \mathrm{~nm}, 62.5 \pm 0.69 \mathrm{~nm}$, $83.4 \pm 0.91 \mathrm{~nm}$ and $104 \pm 1.1 \mathrm{~nm}$ standard deviation. The dry particle sizes were determined using calculations from Knutson and Whitby (1975) that take into account the pressure and temperature measured at the inlet of the CCNc, just after the nanoDMA. Downstream of the nanoDMA, the flow was split between a Droplet Measurement Technologies (DMT) cloud condensation nuclei counter $(\mathrm{CCNc})$ (Roberts and Nenes, 2005; Lance et al., 2006; Rose et al., 2008) and a TSI 3760 condensation particle counter (CPC) modified with a critical orifice at the exhaust line. The nanoDMA was operated with a sheath flow of $6 \mathrm{~L} \mathrm{~min}^{-1}$, while the CCNc and CPC were operated with 0.75 and $1.5 \mathrm{~L} \mathrm{~min}^{-1}$ flow rates, respectively, resulting in a nanoDMA sheath-to-aerosol flow ratio (SAR) of $\sim 2.7$ and a CCNc SAR of 10 . The low nanoDMA SAR (comparable to that used by McMurry et al., 2009) resulted in a transfer function that allowed transmission of particles $35.7-48.8 \mathrm{~nm}$ at the $40 \mathrm{~nm}$ setpoint and $89-$ $124 \mathrm{~nm}$ at the $100 \mathrm{~nm}$ setpoint (for singly charged particles only). A higher sheath flow rate could not have been used to increase the nanoDMA SAR because of the voltages required to classify particles of $\sim 100 \mathrm{~nm}$ diameter with the nanoDMA. The colder end of the CCN column was maintained at $T_{\mathrm{c}}=24.0 \pm 1.38^{\circ} \mathrm{C}$, while the warmer end was maintained at $T_{\mathrm{h}}$ to obtain $\Delta T$ ranging from from $1.87 \pm 0.032^{\circ} \mathrm{C}$ to $13.7 \pm 0.038^{\circ} \mathrm{C}$, corresponding to a range of supersaturations $\sim 0.07-1.15 \%$. For reference, ambient cloud supersaturations are generally $<1 \%$ (Seinfeld and Pandis, 1998). Supersaturation in the $\mathrm{CCNc}$ was calibrated in the field using atomized and classified $\mathrm{NaCl}$ particles, which were also used to simultaneously calibrate the HTDMA system. The activated fraction at the lowest supersaturations can be underestimated at high flow rates if droplets do not grow sufficiently to be detected by the optical particle counter at the exit of the CCN column (Lance et al., 2006). However, particles with diameter $<100 \mathrm{~nm}$ and with atmospherically relevant hygroscopicity are not $\mathrm{CCN}$ active at the lowest supersaturation setpoint $(\sim 0.07 \%)$; any signal will likely be from the presence of multiply charged particles. Since the CCN measurements during MIRAGE were size resolved, overestimation of activation ratios at low supersaturations from large unactivated haze particles is not a significant issue.

For ambient CCN measurements during MIRAGE, every $3 \mathrm{~min}$ the $\mathrm{CCNc}$ supersaturation was increased by $0.12 \%$ and 
the nanoDMA upstream of the CCNc stepped through the same four particle sizes. We exclude the first $56 \mathrm{~s}$ in every 3 min period to allow the instrument supersaturation to reach steady state. Excluding $20 \mathrm{~s}$ after each change in the particle size setpoint leaves $16 \mathrm{~s}$ of $\mathrm{CCN}$ and $\mathrm{CN}$ concentration measurements to average for one "activated fraction". The $40 \mathrm{~nm}$ and $60 \mathrm{~nm}$ data at the lowest supersaturation setpoint are also excluded, resulting in a total of $4.8 \mathrm{~min}$ of measurements excluded from our analysis every time supersaturation was changed from the highest to the lowest setting starting the $30 \mathrm{~min}$ cycle over again. This is comparable to the $5 \mathrm{~min}$ of measurements excluded by Rose et al. (2010), and was deemed sufficient for the higher $\mathrm{CCNc}$ flow rate used in our study $\left(0.75 \mathrm{~L} \mathrm{~min}^{-1}\right.$ instead of $\left.0.5 \mathrm{~L} \mathrm{~min}^{-1}\right)$. Thus, measurements at 8 and 9 supersaturation settings are obtained for $40-60 \mathrm{~nm}$ and $80-100 \mathrm{~nm}$ particles, respectively. The particle concentration measured for a $100 \mathrm{~nm}$ slice of the particle size distribution ranged from 1 to $1000 \mathrm{~cm}^{-3}$ during the study, indicating that the airmass was often quite polluted. Without size classification, water vapor depletion would have been a significant problem in the CCNc (Lathem and Nenes, 2011).

To measure the aerosol hygroscopicity, a humidified tandem differential mobility analyzer (HTDMA) (Rader and McMurry, 1986) was built and deployed. The HTDMA was maintained at a controlled temperature of $32.9 \pm 0.55^{\circ} \mathrm{C}$ using a recirculating air bath. The inlet and central humidity were controlled by mixing moist and dry compressed air supplies to the shell of multitube Permapure Nafion humidifiers. The residence time of the aerosol flow through the Nafion humidifiers was $1.1 \mathrm{~s}$ (diameter of the tubes $=1.523$ $\mathrm{mm}$, length of tubes $=61 \mathrm{~cm}$, number of tubes $=18$, flow rate $=1.07 \mathrm{~L} \mathrm{~min}^{-1}$ ). Humidity was monitored at eight locations within the HTDMA (at the inlet and outlet of both the sample and sheath flows in both DMAs) with Vaisala humidity probes (HMM30C), which have a specified accuracy of $\pm 2 \% \mathrm{RH}$ at $\mathrm{RH}<90 \%$. The average of the $4 \mathrm{RH}$ measurements for each DMA was monitored and controlled using PID controllers, with measured humidity in DMA2 maintained at $88.2 \% \pm 1.2 \% \mathrm{RH}$ throughout the study, while DMA1 was maintained at $<5 \%$ RH. The standard deviation between these $4 \mathrm{RH}$ measurements for DMA2 was $2.2 \%$ on average throughout the project. Calibrations with $20-100 \mathrm{~nm}$ $\mathrm{NaCl}$ aerosol suggest that the humidity was slightly higher than the average measurement, with average growth factor of 2.27 yielding a calibrated RH of $90.4 \% \pm 0.56 \%$ based on $\kappa$ of 1.3 for $\mathrm{NaCl}$ (Petters and Kreidenweis, 2007). Assuming a dynamic shape factor of 1.02 for dry $\mathrm{NaCl}$ particles, the calibrated RH was $91.03 \% \pm 0.50 \%$.

For ambient measurements of aerosol hygroscopicity during MIRAGE, DMA1 was used to classify a different particle size $(20,40,60,80$ and $100 \mathrm{~nm})$ every $6 \mathrm{~min}$, while DMA2 was scanned in thirty $10 \mathrm{~s}$ steps to obtain the size distribution after humidification, covering the range of growth factors from 0.6 to 2.8 . The sheath flows were set to $7 \mathrm{~L} \mathrm{~min}^{-1}$, resulting in a SAR of 6.5 for both DMAs. Each time the volt- age on DMA2 was increased, the first $8 \mathrm{~s}$ of data were excluded and measurements were made over the remaining $2 \mathrm{~s}$. Each time the voltage on either DMA was returned from the maximum back to the minimum setpoint, an additional $60 \mathrm{~s}$ of data were excluded.

Ambient size-resolved mass distribution measurements were obtained using a time-of-flight aerosol mass spectrometer (TOF-AMS) (Cross et al., 2009). In the particle time-offlight (PTOF) mode of the AMS, a mechanical chopper modulates the sampled particle beam, and $5 \mathrm{~min}$ average mass spectra are obtained as a function of particle vacuum aerodynamic diameter $\left(d_{\mathrm{va}}\right)$ (Jayne et al., 2000). The nonrefractory particulate mass distributions (i.e., organics, sulfates, nitrates, ammonium and chloride) were binned logarithmically using 32 bins per decade over the $d_{\mathrm{va}}$ range 20-2000 $\mathrm{nm}$ and normalized to the corresponding mass loadings measured using the mass spectrum (MS) mode of the AMS. $d_{\mathrm{va}}$ was converted to mobility diameter for comparison to the water uptake measurements by dividing by an assumed particle density, $\rho_{p}=1.45 \mathrm{~g} \mathrm{~cm}^{-3}$ (Salcedo et al., 2006), and dynamic shape factor of 1.0 (DeCarlo et al., 2004).

\subsection{CCN Measurements and Derivation of $\kappa_{\mathrm{CCNc}}$}

Every 30 min we obtained "activation spectra" for four particle sizes, covering a range in supersaturations from $0.07 \%$ to $1.15 \%$ (See Fig. 7a-d for examples of CCN activation spectra). A single point on an activation spectrum indicates the fraction of particles with a critical supersaturation $\left(s_{\mathrm{c}}\right)$ less than or equal to the instrument supersaturation $(s)$, where $s=S-1$ (usually expressed as a percentage) and $S$ is the saturation ratio. Each point on a single activation spectrum was taken within 3 min of the adjacent point. We fit the activation spectra to a sigmoidal function of the following form:

$R_{\mathrm{a}}(s)=\frac{E}{1+\left(s / s^{*}\right)^{-C}}$,

where $R_{\mathrm{a}}(s)$ is the fraction of classified particles that activate at critical supersaturations less than or equal to $s, E$ is the upper asymptote of the sigmoid (indicating the fraction of CCN-active particles), $s^{*}$ is the location of the inflection point (indicating the "characteristic" critical supersaturation of the CCN-active particles) and $C$ expresses the slope (indicating the degree of physical and chemical heterogeneity of the $\mathrm{CCN}$-active particles).

The normalized sigmoidal function, $R_{\mathrm{a}}^{*}(s)$, is a 2 parameter log-logistic function (Ashkar and Mahdi, 2006) and can be used to derive the chemical characteristics of the activated particles.

$R_{\mathrm{a}}^{*}(s)=\frac{R_{\mathrm{a}}(s)}{E}=\frac{1}{1+\left(s / s^{*}\right)^{-C}}=\frac{\left(s / s^{*}\right)^{C}}{\left(s / s^{*}\right)^{C}+1}$ 
Differentiating $R_{\mathrm{a}}^{*}(s)$ yields the probability distribution of particles activating at $s=s_{\mathrm{c}}$ (Ashkar and Mahdi, 2006; Lance, 2007):

$p\left(s_{\mathrm{c}}\right)=\frac{d\left(R_{\mathrm{a}}^{*}\left(s_{\mathrm{c}}\right)\right)}{d s}=\left(\frac{C}{s^{*}}\right) \frac{\left(s_{\mathrm{c}} / s^{*}\right)^{C-1}}{\left(1+\left(s_{\mathrm{c}} / s^{*}\right)^{C}\right)^{2}}$.

If all particles in the aerosol population have a single critical supersaturation, $s^{*}, p\left(s_{\mathrm{c}}\right)$ would be a delta function and $R_{\mathrm{a}}^{*}$ would be a step function. Heterogeneity in the chemical composition and particle size both contribute to broadening of $p\left(s_{\mathrm{c}}\right)$ (Lance, 2007; Svenningsson and Bilde, 2008; Rose et al., 2008; Cerully et al., 2011) and affects the slope parameter, $C$, of the activation spectrum.

To unravel these contributions and obtain a measure of the chemical heterogeneity, we express critical supersaturation in terms of hygroscopicity parameter $\kappa$ as follows. The relationship between $\kappa, d_{p}$ and $s_{\mathrm{c}}$ for an individual particle is described by $\kappa$-Köhler theory (Petters and Kreidenweis, 2007):

$\ln \left(s_{\mathrm{c}}+1\right)=\left(\frac{4 A^{3}}{27 \kappa d_{p}^{3}}\right)^{1 / 2}$,

where $A=4 M_{\mathrm{w}} \sigma_{\mathrm{w}} /\left(R T \rho_{\mathrm{w}}\right), M_{\mathrm{w}}, \sigma_{\mathrm{w}}$ and $\rho_{\mathrm{w}}$ are the molecular weight, surface tension and density of pure water, $R$ is the universal gas constant, $T=\left(T_{\mathrm{c}}+T_{\mathrm{h}}\right) / 2$ is the average temperature within the $\mathrm{CCNc}$ column and $d_{p}$ is the particle dry diameter (assumed to be spherical). $s^{*}$ can then be expressed, using Eq. 4, in terms of a "characteristic" hygroscopicity, $\kappa^{*}$ :

$\kappa^{*}=\frac{4 A^{3}}{27 d_{p}^{3}\left(\ln \left(s^{*}+1\right)\right)^{2}}$.

In this study, $\kappa^{*}$ derived from $\mathrm{CCN}$ measurements are referred to as $\kappa_{\mathrm{CCNc}}$. For direct comparison with other $\mathrm{CCN}$ activity studies, we assume in the calculation of $\kappa^{*}$ that there is no surface tension depression from surface active compounds, although filter samples from the $\mathrm{T} 1$ site during the same time period, extracted to CCN-relevant concentrations, showed surface tension depression of 10-15\% compared to pure water, which can introduce a $30-40 \%$ uncertainty in the value of $\kappa$ (Padró et al., 2010). Note that there may be significant covariance between $\kappa_{\mathrm{CCNc}}$ and surface tension, such that the effects of aerosol composition and surface tension cannot be distinguished without additional observational constraints.

If the aerosol population is monodisperse, then $p(\kappa)$ has a width directly related to the chemical heterogeneity of the aerosol and can be described using the sigmoidal fit to the activation curve by directly substituting $s_{\mathrm{c}}$ (in terms of $\kappa$, Eq. (4)) into Eq. (3). However, we cannot neglect the finite width of the DMA transfer function, and we account for its effect on $p(\kappa)$ through application of the well-known error propagation formula:

$\sigma_{s_{\mathrm{c}}}^{2}=\left|\frac{\partial s_{\mathrm{c}}}{\partial d_{p}}\right|^{2} \sigma_{d_{p}}^{2}+\left|\frac{\partial s_{\mathrm{c}}}{\partial \kappa}\right|^{2} \sigma_{\kappa}^{2}+2 \frac{\partial s_{\mathrm{c}}}{\partial d_{p}} \frac{\partial s_{\mathrm{c}}}{\partial \kappa} \operatorname{cov}_{d_{p} \kappa}$,

where $\sigma_{s_{\mathrm{c}}}^{2}$ represents the total variance of $p\left(s_{\mathrm{c}}\right)$ about $s^{*} ; \sigma_{d_{p}}^{2}$ and $\sigma_{\kappa}^{2}$ are the contribution of $d_{p}$ and $\kappa$ variances, respectively, to $\sigma_{s_{\mathrm{c}}}^{2}$. The covariance term, $\operatorname{cov}_{d_{p} \kappa}$, in Eq. (6) is assumed to be negligible, a valid assumption if $d_{p}$ and $\kappa$ are independent over the width of the DMA transfer function. The remaining terms can be derived from Taylor series expansion of Eq. (4) $\left(S_{\mathrm{c}}=s_{\mathrm{c}}+1=\exp (x) \approx 1+x\right.$, where $x=$ $\left(\frac{4 A^{3}}{27 \kappa d_{p}^{3}}\right)^{1 / 2} \approx s_{\mathrm{c}}$, therefore $\partial s_{\mathrm{c}} / \partial d_{p}=-(3 / 2)\left(s_{\mathrm{c}} / d_{p}\right)$ and $\left.\partial s_{\mathrm{c}} / \partial \kappa=-(1 / 2)\left(s_{\mathrm{c}} / \kappa\right)\right)$. Equation (6) then simplifies to

$\frac{\sigma_{s_{\mathrm{c}}}}{s_{\mathrm{c}}}=\sqrt{\left(\frac{3}{2} \frac{\sigma_{d_{p}}}{d_{p}}\right)^{2}+\left(\frac{1}{2} \frac{\sigma_{\kappa}}{\kappa}\right)^{2}}$.

$\sigma_{S_{\mathrm{c}}}$ is determined from the log-logistic sigmoidal fit (Ashkar and Mahdi, 2006) for $C>2$ :

$\sigma_{s_{\mathrm{c}}}=\left(\left(s^{*}\right)^{2}\left(\frac{2 \pi / C}{\sin (2 \pi / C)}-\frac{(\pi / C)^{2}}{\sin ^{2}(\pi / C)}\right)\right)^{1 / 2}$.

$\sigma_{\kappa}$, which is the dispersion in hygroscopicity (and expresses the aerosol chemical heterogeneity), can then be determined from Eq. (7), given estimates for $\sigma_{d_{p}}$ (based on the nanoDMA transfer function), $\sigma_{s_{\mathrm{c}}}$ (from Eq. 8), and $\kappa^{*}$ (from Eq. 5).

To evaluate the effect of mixing state on $\mathrm{CCN}$ concentrations for a given particle size and supersaturation (Sect. 3.4), we calculate $\mathrm{CCN}$ activation spectra as a function of time given different assumptions for $E, \sigma_{\kappa}$ and $\kappa^{*}$. For a given particle size, the fraction of particles with $s_{\mathrm{c}}<s$ is evaluated, first using Eq. (7) to determine $\sigma_{S_{\mathrm{c}}}$, then using Eq. (8) to determine the sigmoidal parameter $\mathrm{C}$, then using Eq. (4) to determine $s_{\mathrm{c}}$, and finally using Eq. (2) to determine $R_{\mathrm{a}}^{*}(s)$. The activated fraction is subsequently multiplied by $E$ and by the classified particle concentrations for that time period and for that particle size to obtain a prediction for the measured CCN concentration at the instrument supersaturation during that time period. For clarification, this is the concentration that would be measured by the $\mathrm{CCN}$ counter for a given $d_{p}$ and $s$ assuming values for $E, \sigma_{\kappa}$ and $\kappa^{*}$. To compare ambient $\mathrm{CCN}$ concentrations at one size to another size, the $\mathrm{CCN}$ concentrations are then inverted. The $\mathrm{CCN}$ distribution, $n_{\mathrm{CCN}}\left(d_{\mathrm{p}}, s\right)=\mathrm{d} N_{\mathrm{CCN}}(s) / \operatorname{dlog} d_{\mathrm{p}}$, is obtained by accounting for charging efficiency and for the width of the nano- DMA transfer function in much the same way that ambient aerosol size distributions are inverted from DMA measurements (Knutson and Whitby, 1975), except that $N_{\mathrm{CCN}}(s)$ 
is the measured $\mathrm{CCN}$ concentration at a given supersaturation for a slice of the ambient particle size distribution selected by the nanoDMA. The same inversion algorithm is applied to both the predicted and measured CCN concentrations.

\subsection{Derivation of $\kappa_{\text {HTDMA }}$}

$\kappa$ is derived from the HTDMA measurements according to the dependence on growth factor $(G F)$, as given by Petters and Kreidenweis (2007):

$\kappa\left(G F, d_{p}\right)=\frac{\left(G F^{3}-1\right) \exp \left(\frac{A}{d_{p} G F}\right)}{\mathrm{RH}}-G F^{3}+1$,

where $G F$ is the ratio of particle size selected by the humidified DMA2 to particle size selected by the dry DMA1 (corresponding to $Z_{p}$ and $Z_{p}^{*}$, respectively, as defined by Rader and McMurry (1986)).

Measured $G F$ distributions are corrected for broadening due to the DMA transfer functions using a procedure called TDMAfit (Stolzenburg and McMurry, 1988). The parameters calculated by TDMAfit for a given measured $G F$ distribution are the mean diameter growth factor $\left(G_{i}\right)$, the diameter spread factor $\left(S_{i}\right)$, and the aerosol number concentration $\left(N_{i}\right)$ for each of up to three Gaussian $G F$ modes. Inverted $G F$ distributions, $p(G F)$, are calculated using Eq. 10. Only TDMAfit results for $\chi^{2}<500$ are reported (Rader and McMurry, 1986).

$p(G F)=\frac{\sum_{i}^{3} \frac{N_{i}}{\sqrt{2 \pi} S_{i} G_{i}} \exp \left[-\frac{1}{2} \frac{\left(G F-G_{i}\right)^{2}}{\left(S_{i} G_{i}\right)^{2}}\right]}{\sum_{i}^{3} N_{i}}$

The "characteristic" hygroscopicity, $\kappa_{\mathrm{HTDMA}}$, is determined by taking a number-weighted average of $p(G F)$, starting with the most hygroscopic particles until the fraction of particles measured by the HTDMA included in the average equals the $\mathrm{CCN}$-active fraction $(E)$. This method for calculating the characteristic hygroscopicity parameter, as given by Eq. 11, does not include the externally mixed non-CCNactive particles in the average, in contrast to the methods reported by Su et al. (2010).

$\kappa_{\mathrm{HTDMA}}=\int_{G F_{\max }}^{G F_{0}} p(G F) \kappa\left(G F, d_{p}\right) d G F$,

where $G F_{0}$ is the limit of integration required to satisfy the criteria $\int_{G F_{\max }}^{G F_{0}} p(G F) d G F=E$. We subsequently compare $\kappa_{\mathrm{HTDMA}}$ and $\kappa_{\mathrm{CCNc}}$ directly, expecting that they represent the same population of particles.

\subsection{Derivation of $\kappa_{\mathrm{AMS}}$}

$\kappa_{\text {AMS }}$ is derived using the PTOF size-resolved mass observations. The mass distributions are first smoothed with a boxcar filter with a window of 10 size bins to reduce noise. Although these are size-resolved measurements, mixing-state information is not retained. The AMS is also limited to measurement of non-refractory material; refractory compounds (such as black carbon in soot and mineral dust) that do not vaporize in the AMS are not detected. $\kappa_{\mathrm{AMS}}$ is given by

$\kappa_{\mathrm{AMS}}=f_{\text {org }} \kappa_{\mathrm{org}}+\left(f_{\mathrm{NH}_{4}}+f_{\mathrm{SO}_{4}}+f_{\mathrm{NO}_{3}}\right) \kappa_{\mathrm{inorg}}$

where $f_{i}$ is the mass fraction of chemical species $i$ in the aerosol, computed from the size-resolved mass loadings of the AMS. In calculation of $\kappa_{\mathrm{AMS}}$, we assume that $\kappa_{\mathrm{org}}=0.1$ and $\kappa_{\text {inorg }}=0.65$, following other megacity studies (Jimenez et al., 2009; Rose et al., 2011; Gunthe et al., 2011). Since the AMS measurements do not provide direct evidence of the aerosol mixing state, another underlying assumption in Eq. 12 is that no refractory material, and that all non-refractory material, is internally mixed in the $\mathrm{CCN}$-active aerosol population. Also note that soot often has a fractal geometry, especially in the size range of interest, which will result in a dynamic shape factor $\chi>1$ and $d_{\mathrm{va}}<\rho_{p} d_{p}$ (DeCarlo et al., 2004; Slowik et al., 2004). Thus, a measured increase in organic mass fraction at smaller particle sizes, as observed at the T0 and T1 sites during the MCMA-2003 campaign (Salcedo et al., 2006), may be partly due to particle shape effects that are unaccounted for.

\section{Results}

The aerosol water uptake properties during MIRAGE 2006 are summarized by a time series of HTDMA and CCNc observations in Fig. 2. Dry particle size distributions are also shown (Fig. 2f), with horizontal lines indicating the lower and upper particle sizes in our analysis. $\kappa_{\mathrm{CCNc}}$ for $100 \mathrm{~nm}$ particles is $0.2 \pm 0.1$ during MIRAGE 2006 , and $\kappa_{\mathrm{CCNc}}$ is often higher for particles smaller than $100 \mathrm{~nm}$ (Fig. 2c). The $\mathrm{CCN}$-active fraction at $\sim 1 \%$ supersaturation ( $E$ from Eq. 1 ) is typically $>70 \%$ for particle sizes $>40 \mathrm{~nm}$ (Fig. $2 \mathrm{~b}$ ), but occasionally drops to $40 \%$ and lower. The hygroscopic growth factors at $\sim 90 \%$ relative humidity for $100 \mathrm{~nm}$ and $40 \mathrm{~nm}$ particles (Fig. 2d and e, respectively) vary between 1.0 and 1.8 throughout the campaign.

\subsection{Diurnal changes in aerosol hygroscopicity}

The dominant trend in Fig. 2 is a daily maximum in hygroscopic growth factor and $\kappa_{\mathrm{CCNc}}$ during the daytime. Figure 1 shows the mixing-state parameters from the $\mathrm{CCN}$ activation spectra. Both parameters in Fig. 1 are independently derived in our analysis, but both show strong diurnal trends. 


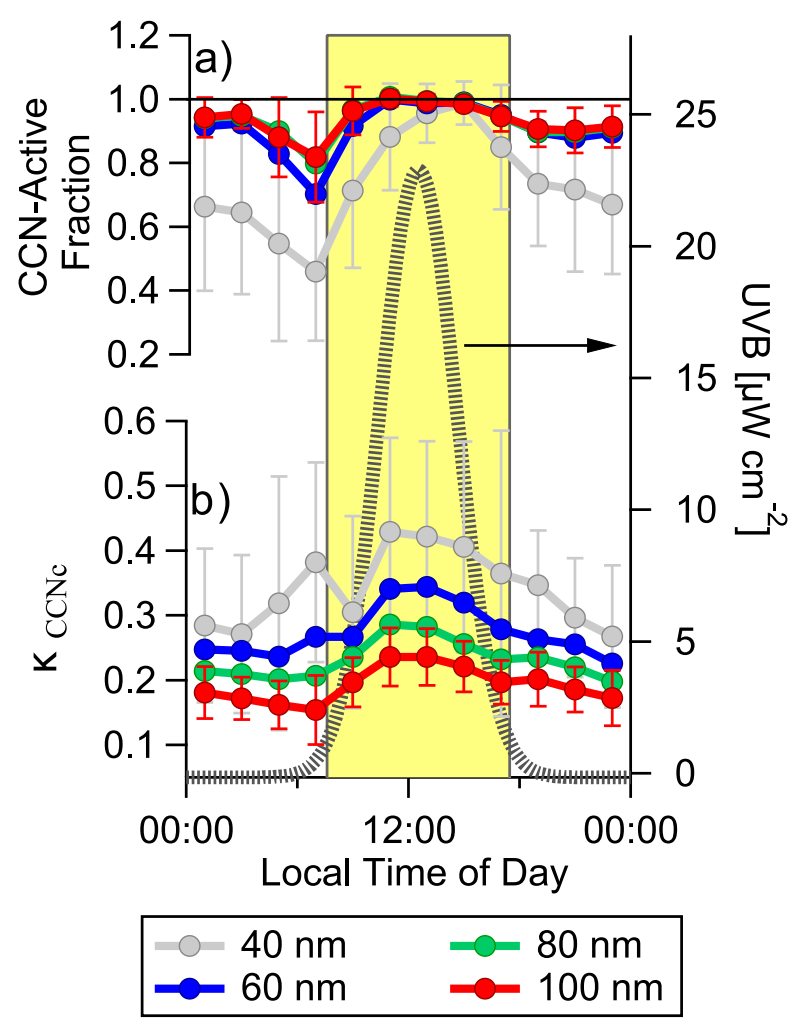

Fig. 1. Campaign average diurnal profile of measured mixing-state properties and composition of 40,60, 80 and $100 \mathrm{~nm}$ aerosol during the MIRAGE 2006 campaign: (a) fraction of particles acting as $\mathrm{CCN}$ at $\sim 1 \%$ supersaturation, (b) hygroscopicity parameter for the $\mathrm{CCN}$-active fraction. Plotted on the right axis is a Gaussian fit to the average ultraviolet solar intensity (UVB) as a function of the local time of day (UTC -6h) during MIRAGE 2006, with the daylight hours between 07:36 and 17:27 ( $\pm 5 \mathrm{~h}$ from solar maximum) highlighted.

During the daytime, the fraction of $\mathrm{CCN}$-active particles increases, coinciding with an increase in $\mathrm{CCN}$ hygroscopicity. There is a strong size dependence for both of these trends, with $40 \mathrm{~nm}$ particles exhibiting higher $\kappa_{\mathrm{CCNc}}$ but lower $\mathrm{CCN}$ active fraction throughout most of the day. However, during the latter half of the daylight hours, the $\mathrm{CCN}$-active fraction for all particle sizes approaches $100 \%$. $\kappa_{\mathrm{CCNc}}$ for all particle sizes reaches a maximum within $1-2 \mathrm{~h}$ of local noon, suggesting that photochemical processes are dominant at that time, which is consistent with the peak in oxygenated organic aerosol mass (Aiken et al., 2009) and water soluble organic carbon mass (Hennigan et al., 2008) observed during the daytime at the $\mathrm{T} 0$ and $\mathrm{T} 1$ sites, respectively.

New particle formation (NPF) events occurred frequently during MIRAGE 2006 (Smith et al., 2008), as illustrated by the particle size distributions (Fig. 2f). The days with the strongest NPF events at the T1 site were the 16, 18, 21, 23 and 24 March (Fig. 3). Weaker and shorter lived NPF events occurred on almost all other days throughout the campaign. In the following analysis, we include only the five days with the strongest NPF events to represent "NPF days", and contrast these days with all other days during the campaign.

The diurnal pattern of aerosol mixing state is also influenced by breakup of the boundary layer and changes in emissions throughout the day. During 06:00-08:00 LT, there is a dramatic decrease in the $\mathrm{CCN}$-active fraction for all particle sizes (Fig. 1), consistent with the greater vehicular emissions during the early morning rush hour and a low boundary layer height (Cross et al., 2009; Velasco et al., 2009; Aiken et al., 2009; Bon et al., 2011; Kalafut-Pettibone et al., 2011). A greater effect of primary motor vehicle emissions on particle sizes $<60 \mathrm{~nm}$ is consistent with emission factors that peak in the 25-32 nm size range (Kalafut-Pettibone et al., 2011).

The ambient CCN concentration $\left(n_{\mathrm{CCN}}\left(d_{\mathrm{p}}, s\right)=\right.$ $\left.\mathrm{d} N_{\mathrm{CCN}}(s) / \mathrm{d} \log d_{\mathrm{p}}\right)$ typically peaks during the daytime, consistent with previous studies in Mexico City (Baumgardner et al., 2004). Smaller particles exhibit greater diurnal changes in $n_{\mathrm{CCN}}\left(d_{\mathrm{p}}, s\right)$. Figure 4 shows the average $n_{\mathrm{CCN}}\left(d_{\mathrm{p}}, s\right)$ on NPF days compared to all other days, as a function of the local time of day and as a function of particle size. For every one of the 5 NPF days, the concentration of $40 \mathrm{~nm}$ CCN exceeded by more than twofold the concentration of $100 \mathrm{~nm} \mathrm{CCN}$ at $s>0.5 \%$ for some fraction of the "daytime" hours $( \pm 5 \mathrm{~h}$ from the solar maximum). For $33 \%$ of the time $n_{\mathrm{CCN}}(40 \mathrm{~nm},>0.5 \% s)$ $>2 n_{\mathrm{CCN}}(100 \mathrm{~nm},>0.5 \% \mathrm{~s})$, and for $52 \%$ of the time $n_{\mathrm{CCN}}(40 \mathrm{~nm},>0.5 \% s)>n_{\mathrm{CCN}}(100 \mathrm{~nm},>0.5 \% s)$, with greater frequency of occurrence under both criteria using a more restrictive definition of "daytime" (e.g., $\pm 2 \mathrm{~h}$ from the solar maximum). On days without strong NPF events $n_{\mathrm{CCN}}\left(d_{\mathrm{p}}, s\right)$ remains relatively constant throughout the day. The biggest difference in $n_{\mathrm{CCN}}\left(d_{\mathrm{p}}, s\right)$ between NPF days and all other days occurs at successively later times during the day as particle size increases from 40 to $100 \mathrm{~nm}$.

The increase in $\kappa_{\mathrm{CCNc}}$ during the daytime is also observed with $\kappa_{\text {HTDMA }}$ (Fig. 5a). However, the nearly constant offset for $\kappa_{\mathrm{CCNc}}$ as a function of particle size is not observed with the HTDMA measurements. $\kappa_{\mathrm{CCNc}}$ and $\kappa_{\mathrm{HTDMA}}$ agree well for $100 \mathrm{~nm}$ particles (Fig. 5a), but $\kappa_{\mathrm{CCNc}}>\kappa_{\mathrm{HTDMA}}$ for $40 \mathrm{~nm}$ particles. Differences between subsaturated and supersaturated hygroscopicity may occur, especially at high $f_{\text {org }}$, if aerosol constituents are slightly soluble or if they depress surface tension, which depends on the concentration of dissolved solute in the deliquesced haze particle or droplet (Padró et al., 2010).

\subsection{Aerosol chemical composition}

The size-resolved AMS measurements show that the organic mass fraction $\left(f_{\text {org }}\right)$ typically exceeds $50 \%$ for all particle sizes analyzed, and regularly approaches $100 \%$ during the morning for $40 \mathrm{~nm}$ particles (Fig. 5b). The diurnal profile shows a decrease in $f_{\text {org }}$ during the daytime for all particle 


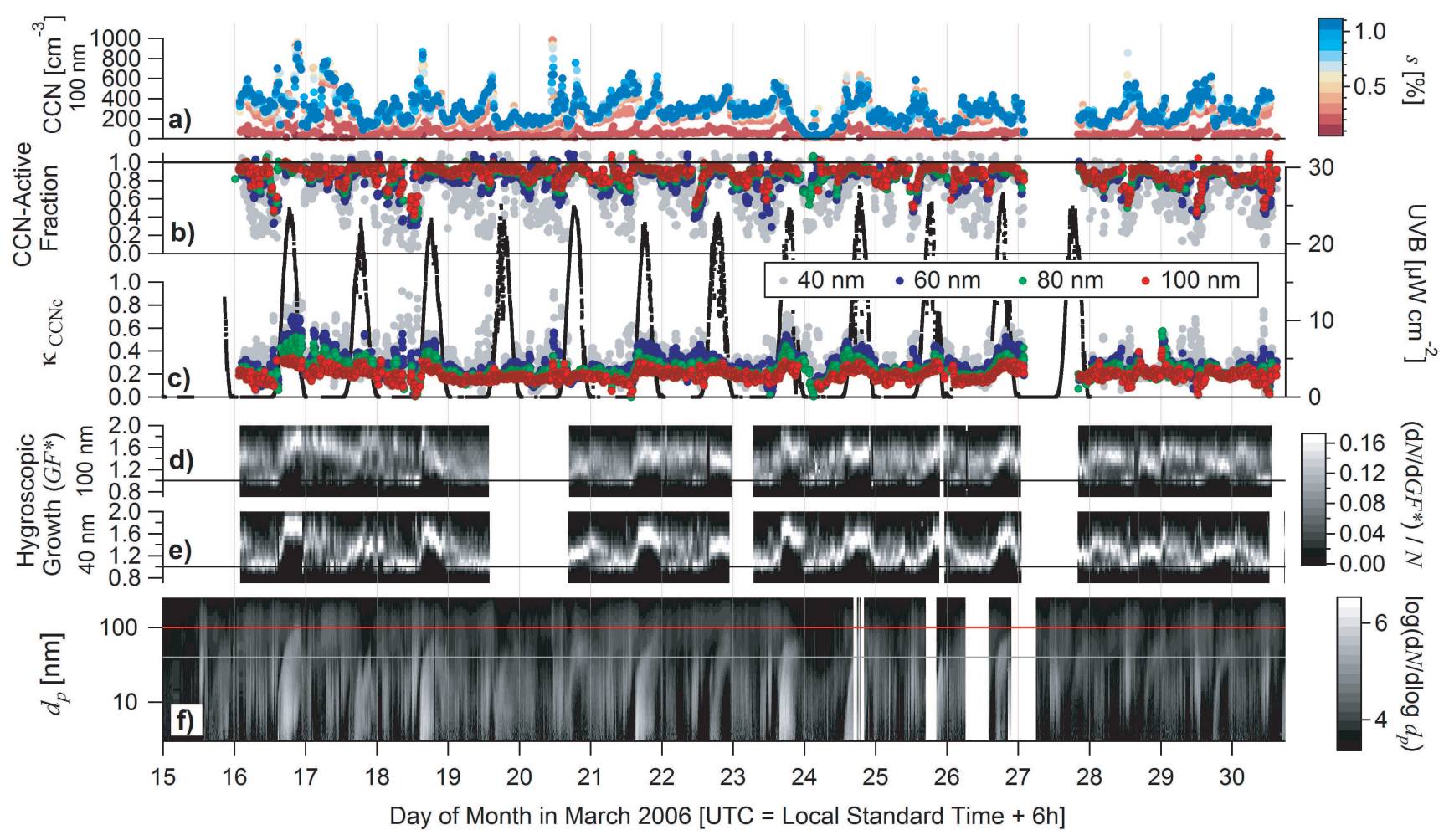

Fig. 2. Overview time series of measured aerosol microphysical properties during the MIRAGE 2006 campaign: (a) number concentration of $100 \mathrm{~nm}$ particles acting as $\mathrm{CCN}$, (b) fraction of particles acting as $\mathrm{CCN}$ at $\sim 1 \%$ supersaturation, (c) hygroscopicity parameter for the $\mathrm{CCN}$-active fraction, hygroscopic diameter growth factor distribution for (d) $100 \mathrm{~nm}$ and (e) $40 \mathrm{~nm}$ particles, and (f) aerosol size distribution for 3-250 nm particles, with $40 \mathrm{~nm}$ and $100 \mathrm{~nm}$ highlighted in grey and red, respectively. In (b) and (c), parameters are reported for 40, 60, 80 and $100 \mathrm{~nm}$ selected dry particle diameters. The growth factor distributions in (d) and (e) are normalized to particle number concentrations.

sizes. $f_{\text {org }}$ for $40 \mathrm{~nm}$ particles remains high for $\sim 2$ additional hours in the morning, compared to the other particle sizes.

An inverse relationship is observed between $\kappa_{\mathrm{CCNc}}$ and $f_{\text {org }}$ (Fig. 6), with a slope that typically falls within the range from several other studies (Dusek et al., 2010; Rose et al., 2011; Gunthe et al., 2011; Cerully et al., 2011). For $100 \mathrm{~nm}$ particles $\kappa_{\text {inorg }}=0.46 \pm 0.014$ and $\kappa_{\text {org }}=$ $0.04 \pm 0.029$, while for $40 \mathrm{~nm}$ particles $\kappa_{\text {inorg }}=0.94 \pm 0.074$ and $\kappa_{\text {org }}=0.21 \pm 0.12 . \kappa_{\text {inorg }}$ for the MIRAGE 2006 dataset increases for smaller particle sizes, but the variability and uncertainty increase as well. The $100 \mathrm{~nm}$ observations are more robust than the $40 \mathrm{~nm}$ observations because two independent datasets yield comparable values for $\kappa^{*}$ (Fig. 5a) and also because the mass of $100 \mathrm{~nm}$ particles is typically much greater than for $40 \mathrm{~nm}$ particles, resulting in much lower uncertainty for $f_{\text {org }}$.

\subsection{Averaging by time period}

To further highlight the dominant factors influencing the evolution of the aerosol mixing state throughout the day, we average the distributions of supersaturated and subsaturated hygroscopicity during MIRAGE 2006 over different time periods: (1) daytime (08:00-16:00 LT) on NPF days,
(2) daytime on all other days, (3) all times of day over the whole campaign, and (4) during the early morning rush hour (06:00-08:00 LT). Since these are size-resolved measurements, changes in the CCN activation spectra and GF distributions during different time periods are due to changes in the aerosol chemical composition and mixing state.

NPF events and primary vehicular emissions often exhibit competing effects on the $\mathrm{CCN}$-active fraction, especially for smaller particles. The greater effect of both NPF events and the morning rush hour on smaller particles is not surprising since NPF leads to a strong Aitken mode and since primary motor vehicle emissions during MIRAGE peak in number concentration in the $25-32 \mathrm{~nm}$ size range (Kalafut-Pettibone et al., 2011). For all particle sizes, the fraction of particles in the nonhygroscopic mode (GF centered at $1.0 \pm 0.03$ ) is highest during the early morning rush hour, and lowest during the daytime on NPF days (Fig. 7e-h). The CCN-active fractions are also at their lowest and highest, respectively, during these time periods (Fig. 7a-d). The greatest change in the hygroscopicity of the $\mathrm{CCN}$-active aerosol population occurs between the morning rush hour and the daytime on NPF days (Fig. 7). The hygroscopic mode during the morning rush hour becomes more hygroscopic during the daytime 


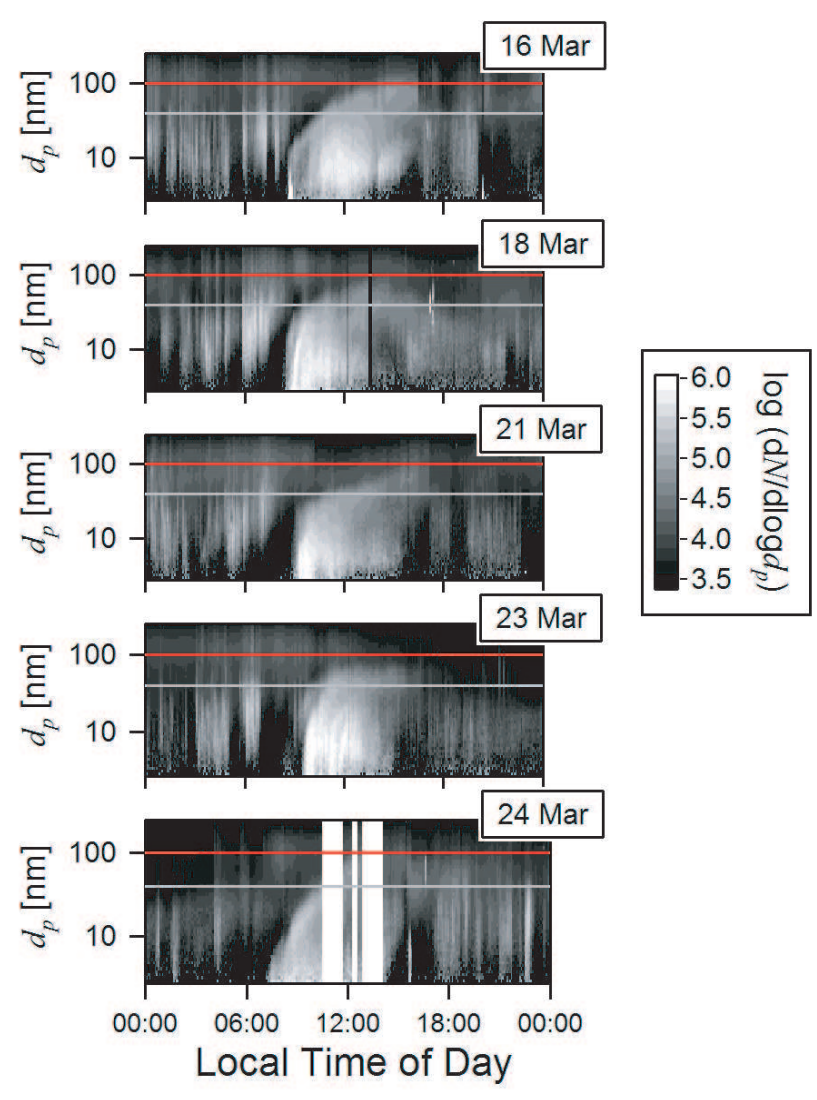

Fig. 3. Particle size distributions on "NPF days", days during which strong new particle formation events occurred. Particles with $40 \mathrm{~nm}$ and $100 \mathrm{~nm}$ diameters are highlighted with horizontal grey and red lines, respectively.

on NPF days, increasing from a mean modal GF of 1.341.41 to $1.48-1.51$, while $s^{*}$ changes by as much as $20 \%$ on average between these two time periods.

The increase in hygroscopicity for the $\mathrm{CCN}$-active population during the daytime may be due to several different mechanisms: (1) growth of new particles during NPF events (by coagulation with other newly formed particles or by condensational growth of secondary species), (2) growth of primary particles by coagulation with particles formed during NPF events, (3) growth of primary particles by condensation of secondary species, and (4) photo-oxidation of constituents already present within the aerosol. It is not simple to evaluate which of these mechanisms are playing a dominant role since several or all of them may be acting at the same time. However, the water uptake distributions provide several clues. For $100 \mathrm{~nm}$ particles, the CCN activation spectra (Fig. 7a) and the GF distributions (Fig. 7e, i) are nearly the same during the daytime whether or not strong NPF events occur. This suggests that the third and/or fourth mechanism(s) have a dominant impact on the observed diurnal trend for $100 \mathrm{~nm}$ particles. For $40-80 \mathrm{~nm}$ particles, although the $\mathrm{CCN}$-active fraction remains the same during the daytime whether or not
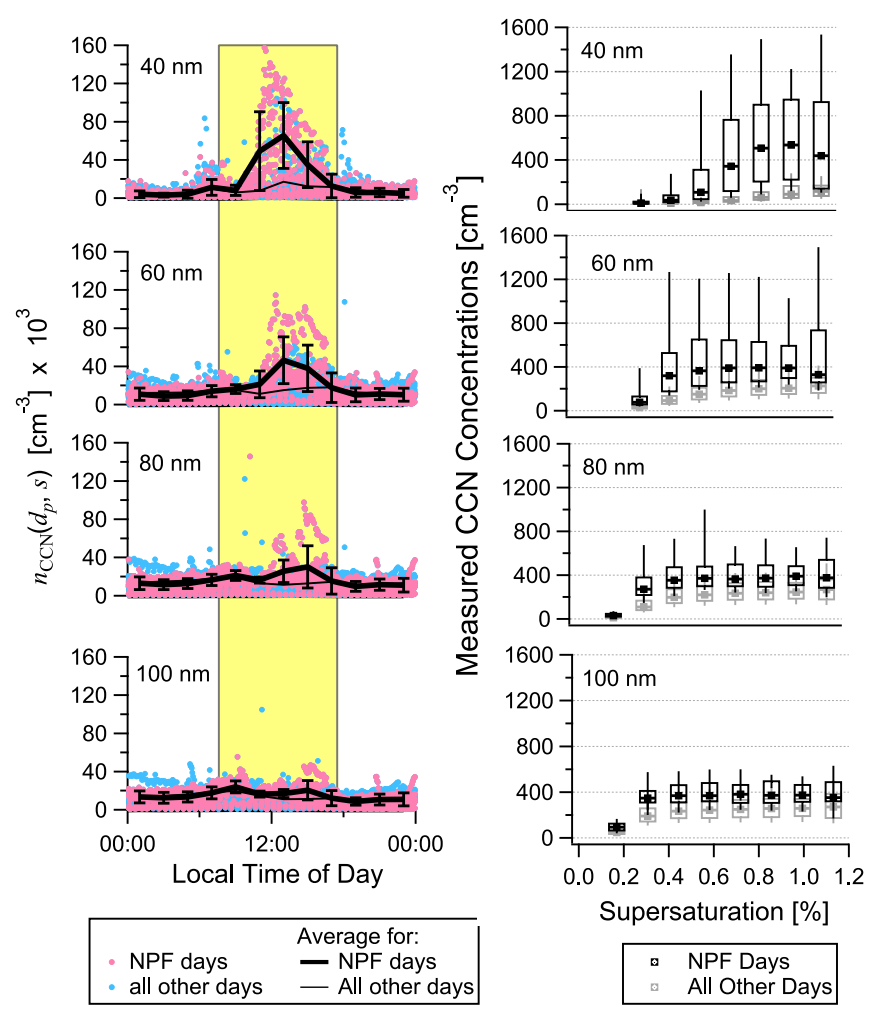

Fig. 4. Diurnal profile of inverted CCN concentrations on days with strong new particle formation (NPF) events, and for all other days, as a function of particle size, with $2 \mathrm{~h}$ average $\mathrm{CCN}$ concentrations at $s>0.5 \%$ overlaid. Also shown are quartiles of measured CCN concentrations on NPF days and on all other days as a function of the instrument supersaturation and particle size.

NPF events occur, the chemical heterogeneity of the CCN decreases during NPF events, as evidenced by both greater slopes for the CCN activation spectra and narrower GF distributions. This implies a greater impact from NPF events for this size range, and therefore a greater role for the first and/or second mechanisms. However, the third and fourth mechanisms may play an important role for $40-80 \mathrm{~nm}$ particles on days when strong NPF events do not occur since primary particles in the nonhygroscopic mode that are present in the morning apparently attain soluble material during the daytime (as evidenced by a distinct GF mode at 1.2 with simultaneous loss of the nonhygroscopic mode, Fig. $7 \mathrm{j}-1$ ). On NPF days, the third and fourth mechanisms appear to be less important for $40-80 \mathrm{~nm}$ particles due to less significant contribution of aged primary particles compared to the concentration of newly formed particles.

The increase in both $\kappa_{\mathrm{CCNc}}$ and $\kappa_{\mathrm{HTDMA}}$ during NPF events is contrary to the observations of Dusek et al. (2010), where NPF was shown to correlate with increased organic mass fraction and decreased hygroscopicity. This is in spite of the fact that $f_{\text {org }}$ is typically $>0.5$ for all particle sizes 


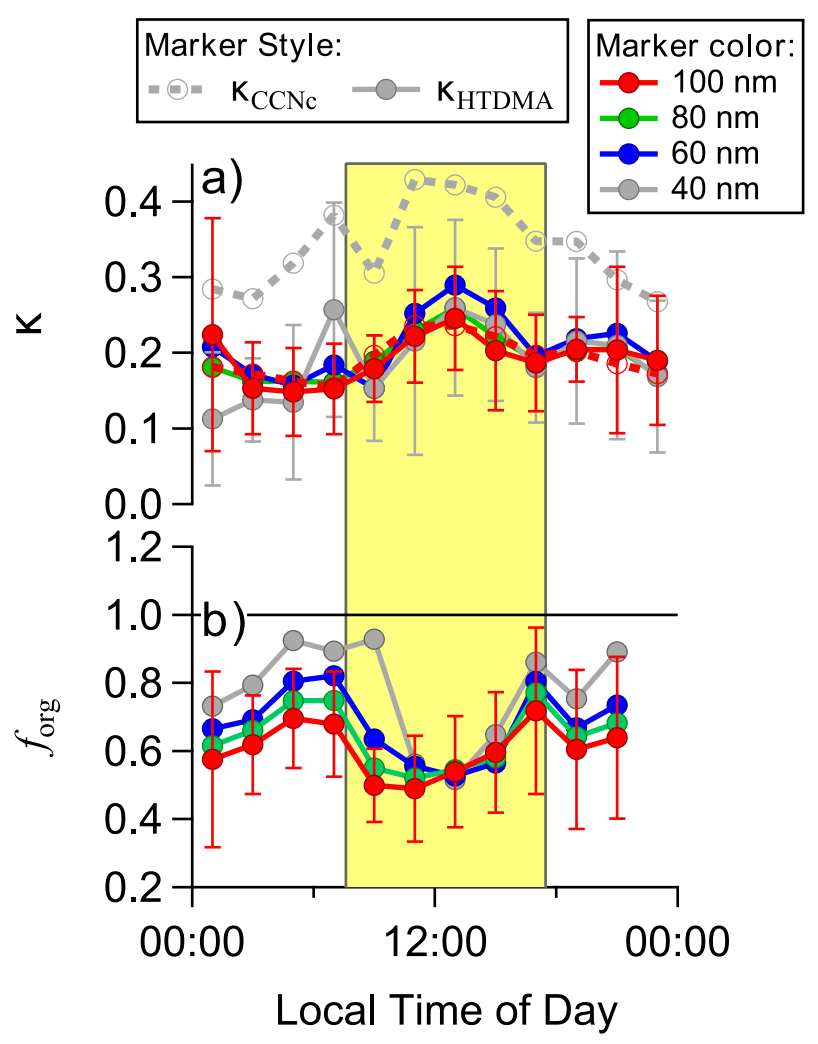

Fig. 5. (a) Campaign average diurnal profile of $\kappa_{\mathrm{CCNc}}$ (dashed) and $\kappa_{\text {HTMDA }}$ (solid) for different particle sizes (indicated by color). For clarity, only $\kappa_{\mathrm{CCNc}}$ for $100 \mathrm{~nm}$ and $40 \mathrm{~nm}$ particles are shown since these observations are already given in Fig. 1. (b) Average diurnal profile of size-resolved organic mass fractions.

during the daytime in Mexico City and the fact that organics were shown to contribute substantially to the growth of particles 10-35 nm during NPF events (Smith et al., 2008). Conversely, Sihto et al. (2011), Hameri et al. (2001) and Ehn et al. (2007) showed that NPF events were correlated with an increase in particle hygroscopicity during NPF events, consistent with our results.

Figure 8 shows the average aerosol composition, hygroscopicity and mixing-state observations as a function of particle size for the same specified time periods as in Fig. 7. The dominant trends are an increase in $\mathrm{CCN}$-active fraction and a decrease in $f_{\text {org }}$ with particle size (Fig. 8a). Differences in mixing state could explain why $\kappa_{\mathrm{CCNc}}$ does not follow the same trend as $\kappa_{\mathrm{AMS}}$; for all time periods, $\kappa_{\mathrm{CCNc}}$ decreases with particle size, whereas $\kappa_{\text {AMS }}$ remains constant or increases with size (Fig. 8b). An external mixture of measured organic compounds (assumed to be internally mixed in calculation of $\kappa_{\mathrm{AMS}}$ ) would result in $\kappa_{\mathrm{AMS}}<\kappa_{\mathrm{CCNc}}$. Evidence for this occurring is the fact that when the CCNactive fraction for $40 \mathrm{~nm}$ particles approaches 1.0 (i.e., during the daytime and especially during NPF events), $\kappa_{\text {AMS }}$ approaches $\kappa_{\mathrm{CCNc}}$. Increasing $\kappa_{\text {inorg }}$ by a small and realis-

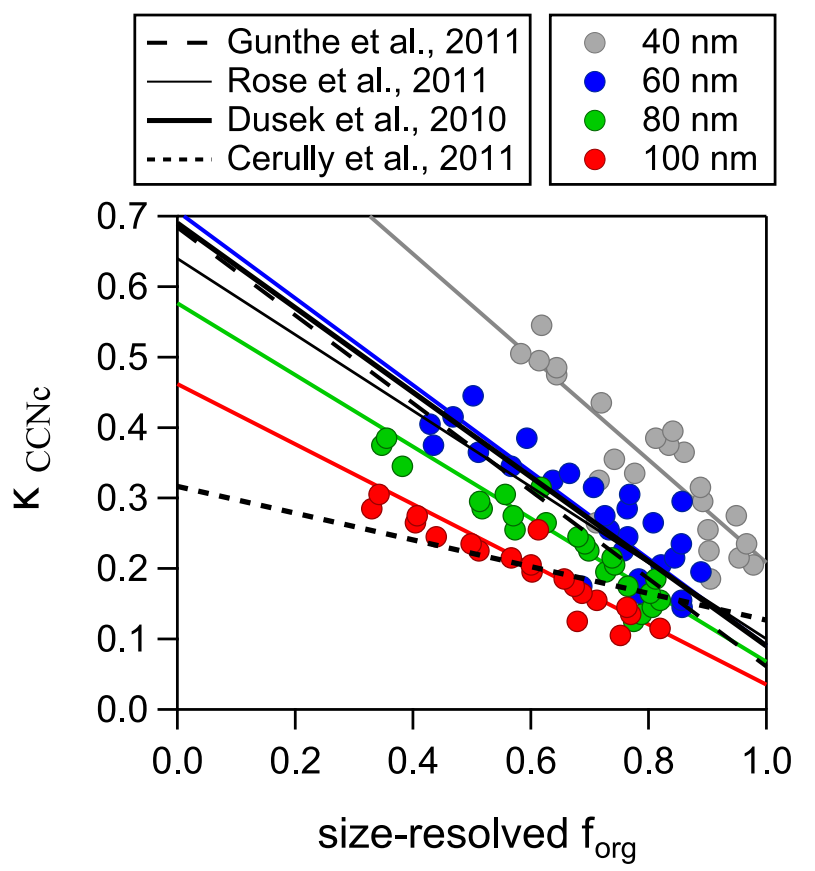

Fig. 6. $\kappa_{\mathrm{CCNc}}$ versus organic mass fraction, as a function of particle diameter. Linear fits as a function of particle size are shown with solid colored lines. Also shown are linear fits found in other polluted and remote environments.

tic amount (from 0.65 to 0.7 ) in calculation of $\kappa_{\text {AMS }}$ would reduce the discrepancy with $\kappa_{\mathrm{CCNc}}$ further. However, when the $\mathrm{CCN}$-active fraction for $40 \mathrm{~nm}$ particles is only 0.5 (i.e., during the early morning rush hour) $\kappa_{\mathrm{AMS}}<\kappa_{\mathrm{CCNc}}$, which is also consistent with this hypothesis, suggesting that much of the measured organic mass is externally mixed to the $\mathrm{CCN}$ active aerosol population during this time period. In addition, an internal mixture of refractory components (not measured by the AMS) would explain why $\kappa_{\mathrm{AMS}}>\kappa_{\mathrm{CCNc}}$, as seen for $100 \mathrm{~nm}$ particles during all time periods. Single particle measurements at the $\mathrm{T} 1$ site show that primary particles $>350 \mathrm{~nm} d_{\mathrm{va}}$ containing hydrocarbon-like organic aerosol (HOA) compounds linked to combustion sources "became internally mixed particles (i.e., were coated with photochemical products) in $\sim 15-30 \mathrm{~min}$ during the mid to late morning (09:00-12:00 LT )" (Cross et al., 2009). Although the single particle measurements represent particles that are at least two times larger than the $100 \mathrm{~nm}$ particles in our analysis, it provides further support to the hypothesis that the externally mixed primary particles emitted during the morning rush hour rapidly grow into larger particles, either through condensation of secondary inorganic and organic species or by coagulation with other particles, leading to larger particles that are internally mixed (and likely contain refractory material). Moffet and Prather (2009) similarly showed evidence that rapid (less than $3 \mathrm{~h}$ ) aging of soot particles in Mexico City is likely dominated by photochemical processes that 


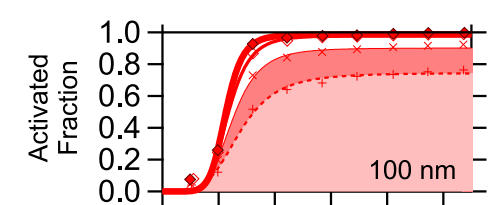

a)

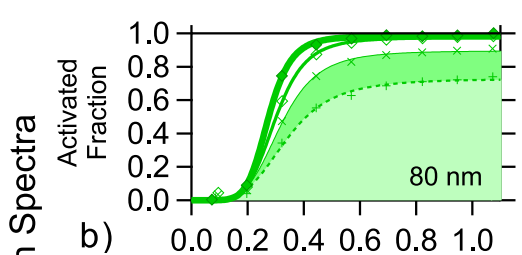

b) $\quad 0.00 .20 .4 \quad 0.6 \quad 0.81 .0$
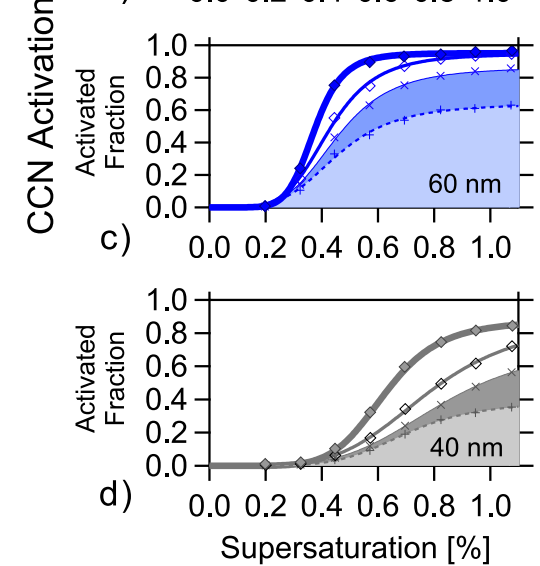
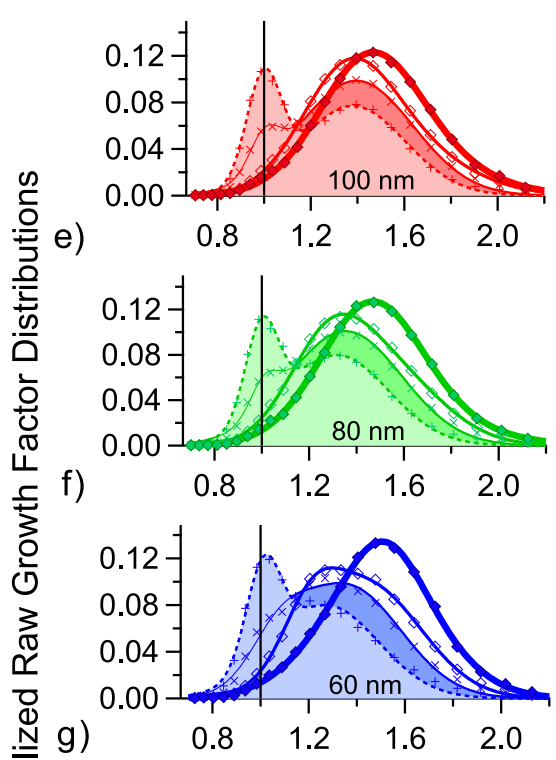

h)

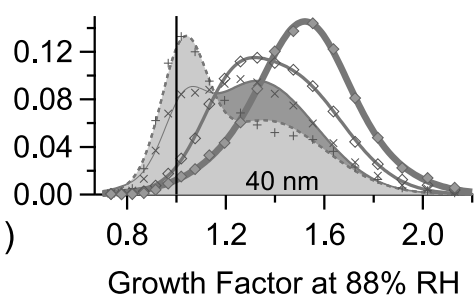

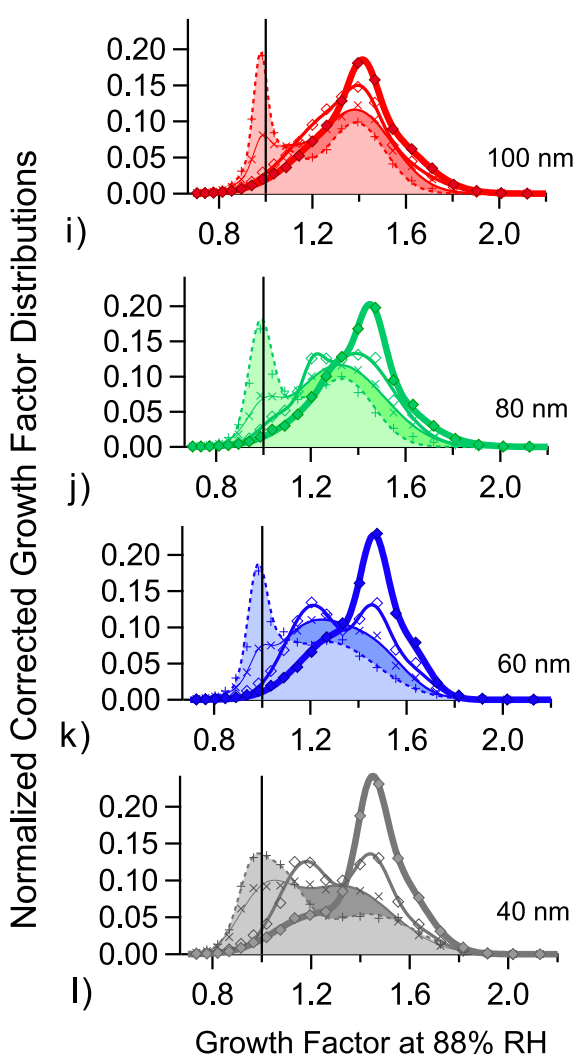

Growth Factor at $88 \% \mathrm{RH}$

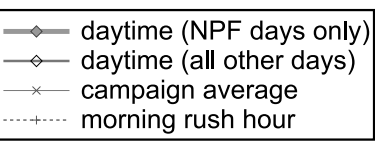

Fig. 7. CCN activation curves (a-d), raw growth factor distributions (e-h) and inverted growth factor distributions (i-l) averaged over different time periods and colored by particle size.

lead to condensation of nitrate, sulfate and organic components onto fresh soot emissions.

\subsection{Effect of mixing state on CCN concentrations}

To evaluate the impact of mixing state and composition on the observed $\mathrm{CCN}$ concentrations, we calculate $\mathrm{CCN}$ activation spectra with different assumptions for $E, \sigma_{\kappa}$ and $\kappa^{*}$. The simulated activation spectra are then multiplied by the measured size-classified particle concentrations to determine the calculated $\mathrm{CCN}$ concentrations, which are then compared to measured $\mathrm{CCN}$ concentrations at each supersaturation in the $\mathrm{CCN}$ activation spectra.

First, we constrain the simulated $\mathrm{CCN}$ activation spectra with $\kappa_{\mathrm{CCNc}}, E$ and $\sigma_{\kappa}$, as determined from the $\mathrm{CCN}$ measurements, to evaluate the uncertainty in the method, which yields linear correlation coefficients of $R^{2}=0.949-0.990$ and slopes of $0.945-0.996$ for calculated versus measured CCN concentrations (Fig. 9a). Uncertainty in calculated CCN concentrations constrained by these $\mathrm{CCNc}$-derived parameters arises mainly from variability in the $\mathrm{CCN}$ concentrations at timescales $<30 \mathrm{~min}$ and $>16 \mathrm{~s}$, which manifests as random scatter of the observed $R_{\mathrm{a}}(S)$ about the sigmoidal fits.

Next, we assume that $\kappa^{*}=\kappa_{\text {AMS }}$. Despite clear differences in $\kappa^{*}$ derived independently from $\mathrm{CCNc}$ and AMS data (Fig. 8b), we find that measured CCN concentrations can be depicted reasonably well with $\kappa_{\text {AMS }}$ when accurate mixing state information is available, yielding linear correlation coefficients of $R^{2}=0.878-0.935$ and slopes of $0.868-0.970$ for calculated versus measured CCN concentrations (Fig. 9b).

Finally, to evaluate the effect of mixing state on measured CCN concentrations, we assume that $E=1.0$ and $\sigma_{\kappa}=0$, yielding linear correlation coefficients of $R^{2}=0.866-0.943$ and slopes of 0.969-1.05 (Fig. 9c). By analyzing the data as a function of the local time of day, we find that mixing-state information is important for describing $\mathrm{CCN}$ concentrations during the morning rush hour, when $E$ is often $<\sim 0.8$. Under these conditions, the calculated $\mathrm{CCN}$ concentrations often overestimate the measured CCN concentrations by $50 \%$ or more. At the highest CCN concentrations $\left(>500 \mathrm{~cm}^{-3}\right.$, calculated $\mathrm{CCN}$ concentrations agree well with measured 

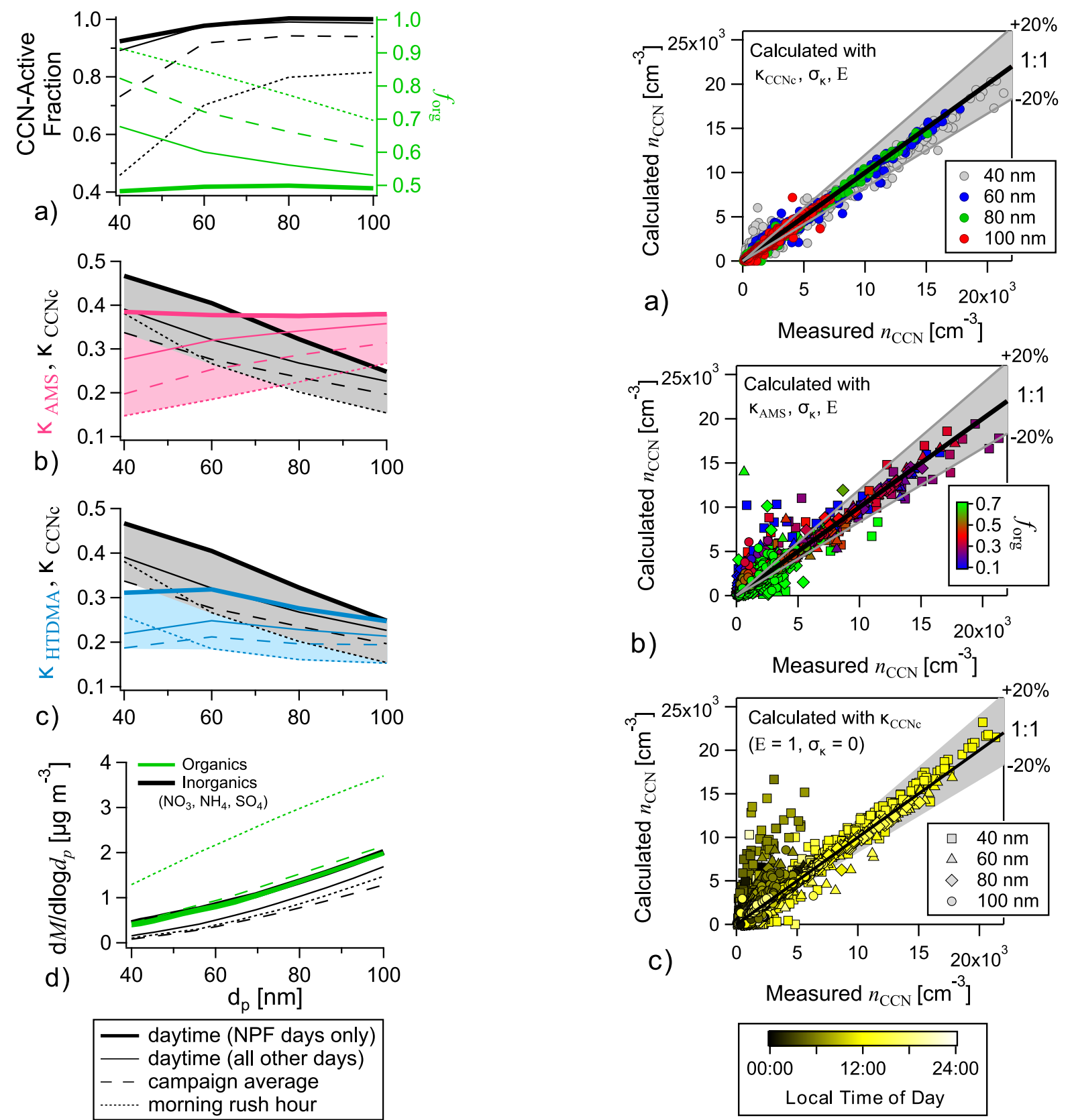

Fig. 8. Size-resolved aerosol mixing state, hygroscopicity and composition, averaged over different time periods.

concentrations because the highest $\mathrm{CCN}$ concentrations occur during the daytime as a result of NPF events when $E$ approaches 1.0 and when the chemical heterogeneity of the $\mathrm{CCN}$-active aerosol population is at a minimum.

These results are consistent with Wang et al. (2010), who found that the fraction of externally mixed particles was important for predicting $\mathrm{CCN}$ concentrations during the early morning rush hour (060:0-08:00 LT) at the T0 site during MILAGRO, and that CCN concentrations during the daytime

Fig. 9. Size-resolved CCN concentrations calculated from three different methods: (a) using $\mathrm{d}_{\mathrm{p}}, \sigma_{\mathrm{d}_{\mathrm{p}}}, \kappa_{\mathrm{CCNc}}, E$ and $\sigma_{\kappa}$; (b) the same as in (a) but using $\kappa_{\mathrm{AMS}}$ instead of $\kappa_{\mathrm{CCNc}}$; and (c) the same as in (a) but not accounting for the aerosol chemical heterogeneity $(E=1$ and $\sigma_{\kappa}=0$ ). Calculated $\mathrm{CCN}$ concentrations are compared to measured $\mathrm{CCN}$ concentrations for a given classified particle size. Markers are colored by local time of day in (c).

(10:00-16:00 LT) could be described adequately (to within $\sim 20 \%$ ) assuming an internal mixture. 


\section{Conclusions}

We obtained CCN activation spectra for a 2-week groundbased study at the T1 site outside of Mexico City during MIRAGE 2006, from which the size-resolved chemical composition and mixing state of particles $40-100 \mathrm{~nm}$ is inferred. Aerosol hygroscopicity was simultaneously measured with a HTDMA covering the same particle size range. The major trend observed is a diurnal pattern with greater concentration and fraction of $\mathrm{CCN}$ during the daytime and also greater characteristic hygroscopicity parameter, $\kappa^{*}$, during the daytime. New particle formation events and the daily early morning rush hour are found to have dominant influences on the aerosol composition and mixing state in the studied size range. $\kappa^{*}$ is compared to size-resolved organic mass fraction, and a linear fit is obtained, with slope that is comparable to slopes found in several other studies.

$\kappa^{*}$ derived from bulk aerosol composition measurements implies constant or increasing hygroscopicity with size, in contrast with the water uptake measurements. We hypothesize that externally mixed nonrefractory material (which is measured by the AMS but does not affect the CCNactive aerosol population) can explain why $\kappa_{\mathrm{CCNc}}>\kappa_{\mathrm{AMS}}$ for smaller particles, while internally mixed refractory material (which is not measured by the AMS but does affect the $\mathrm{CCN}$-active aerosol population) can explain why larger particles exhibit $\kappa_{\mathrm{AMS}}>\kappa_{\mathrm{CCNc}}$.

In conclusion, we find that $\mathrm{CCN}$ concentrations can often be described well using either $\kappa_{\mathrm{AMS}}$ or $\kappa_{\mathrm{CCNc}}$. However, during the early morning rush hour, the $\mathrm{CCN}$-active fraction was often $<0.8$, and $\mathrm{CCN}$ concentrations were often overpredicted by $>50 \%$ when the aerosol mixing state was not considered.

Acknowledgements. S. Lance was supported by a Georgia Tech Presidential Fellowship and NCAR ASP Fellowship. A. Nenes acknowledges support from an NSF CAREER grant. T. Raatikainen acknowledges funding support from the Finnish Cultural Foundation. University of Minnesota researchers were supported by DOE grant DE-FG-02-05ER63997. T. Onasch and D. Worsnop acknowledge DOE grant DE-FG02-05ER63982 and NSF grant ATM-0528170. Thanks to Jeff Gaffney and Nancy Marley at the University of Arkansas at Little Rock for meteorological and ultraviolet solar insolation data at the T1 site during MIRAGE 2006. X.-Y. Yu acknowledges the support from the DOE Biological and Environmental (BER) Atmospheric System Research (ASR) grant under contract DE-AC05-76RLO1830/KP1701000/57131. PNNL is operated by the US DOE by Battelle Memorial Institute.This work was also supported by NOAA climate and air quality programs.

Edited by: L. Molina

\section{Disclaimer}

US government work not protected by US copyright laws. The use of trade, firm, or corporation names in this publication is for the information and convenience of the reader. Such use does not imply an official endorsement or approval by the University of Colorado, the United States Department of Commerce or the National Oceanic and Atmospheric Administration of any product or service to the exclusion of others that may be suitable.

\section{References}

Aiken, A. C., Salcedo, D., Cubison, M. J., Huffman, J. A., DeCarlo, P. F., Ulbrich, I. M., Docherty, K. S., Sueper, D., Kimmel, J. R., Worsnop, D. R., Trimborn, A., Northway, M., Stone, E. A., Schauer, J. J., Volkamer, R. M., Fortner, E., de Foy, B., Wang, J., Laskin, A., Shutthanandan, V., Zheng, J., Zhang, R., Gaffney, J., Marley, N. A., Paredes-Miranda, G., Arnott, W. P., Molina, L. T., Sosa, G., and Jimenez, J. L.: Mexico City aerosol analysis during MILAGRO using high resolution aerosol mass spectrometry at the urban supersite (T0) - Part 1: Fine particle composition and organic source apportionment, Atmos. Chem. Phys., 9, 6633-6653, doi:10.5194/acp-9-6633-2009, 2009.

Andreae, M. O. and Rosenfeld, D.: Aerosol-cloud-precipitation interactions. Part 1. The nature and sources of cloud-active aerosols, Earth-Sci. Rev., 89, 13-41, 2008.

Ashkar, F. and Mahdi, S.: Fitting the log-logistic distribution by generalized moments, J. Hydrol., 328, 694-703, 2006.

Baumgardner, D., Raga, G. B., and Muhlia, A.: Evidence for the formation of $\mathrm{CCN}$ by photochemical processes in Mexico City, Atmos. Environ., 38, 357-367, 2004.

Bon, D. M., Ulbrich, I. M., de Gouw, J. A., Warneke, C., Kuster, W. C., Alexander, M. L., Baker, A., Beyersdorf, A. J., Blake, D., Fall, R., Jimenes, J. L., Herndon, S. C., Huey, L. G., Knighton, W. B., Ortega, J., Springston, S., and Vargas, O.: Measurements of volatile organic compounds at a suburban ground site (T1) in Mexico City during the MILAGRO 2006 campaign: measurement comparison, emission ratios, and source attribution, Atmos. Chem. Phys., 11, 2399-2421, doi:10.5194/acp-11-23992011, 2011.

Cerully, K. M., Raatikainen, T., Lance, S., Tkacik, D., Tiitta, P., Petäjä, T., Ehn, M., Kulmala, M., Worsnop, D. R., Laaksonen, A., Smith, J. N., and Nenes, A.: Aerosol hygroscopicity and CCN activation kinetics in a Boreal forest environment during the 2007 EUCAARI Campaign, Atmos. Chem. Phys., 11, 12369-12386, doi:10.5194/acp-11-12369-2011, 2011.

Chen, D.-R., Pui, D. Y. H., Hummes, D., Fissan, H., Quant, F. R., and Sem, G. J.: Design and evaluation of a nanometer aerosol differential mobility analyzer (Nano-DMA), J. Aerosol Sci., 29, 497-509, 1998.

Cross, E. S., Onasch, T. B., Canagaratna, M., Jayne, J. T., Kimmel, J., Yu, X.-Y., Alexander, M. L., Worsnop, D. R., and Davidovits, P.: Single particle characterization using a light scattering module coupled to a time-of-flight aerosol mass spectrometer, Atmos. Chem. Phys., 9, 7769-7793, 2009,

http://www.atmos-chem-phys.net/9/7769/2009/. 
DeCarlo, P. F., Slowik, J. G., Worsnop, D. R., Davidovits, P., and Jimenez, J. L.: Particle morphology and density characterization by combined mobility and aerodynamic diameter measurements. Part 1: Theory, Aeros. Sci. Technol., 38, 1185-1205, doi:10.1080/027868290903907, 2004.

Dusek, U., Frank, G. P., Curtius, J., Drewnick, F., Schneider, J., Kürten, A., Rose, D., Andreae, M. O., Borrmann, S., and Pöschl, U.: Enhanced organic mass fraction and decreased hygroscopicity of cloud condensation nuclei $(\mathrm{CCN})$ during new particle formation events, Geophys. Res. Lett., 37, L03804, doi:10.1029/2009GL040930, 2010.

Ehn, M., Petäjä, T., Aufmhoff, H., Aalto, P., Hämeri, K., Arnold, F., Laaksonen, A., and Kulmala, M.: Hygroscopic properties of ultrafine aerosol particles in the boreal forest: diurnal variation, solubility and the influence of sulfuric acid, Atmos. Chem. Phys., 7, 211-222, doi:10.5194/acp-7-211-2007, 2007.

Fast, J. D., de Foy, B., Acevedo Rosas, F., Caetano, E., Carmichael, G., Emmons, L., McKenna, D., Mena, M., Skamarock, W., Tie, X., Coulter, R. L., Barnard, J. C., Wiedinmyer, C., and Madronich, S.: A meteorological overview of the MILAGRO field campaigns, Atmos. Chem. Phys., 7, 2233-2257, doi:10.5194/acp-7-2233-2007, 2007.

Gunthe, S. S., Rose, D., Su, H., Garland, R. M., Achtert, P., Nowak, A., Wiedensohler, A., Kuwata, M., Takegawa, N., Kondo, Y., Hu, M., Shao, M., Zhu, T., Andreae, M. O., and Pöschl, U.: Cloud condensation nuclei $(\mathrm{CCN})$ from fresh and aged air pollution in the megacity region of Beijing, Atmos. Chem. Phys., 11, 1102311039, doi:10.5194/acp-11-11023-2011, 2011.

Hämeri, K., Väkevä, M., Aalto, P. P., Kulmala, M., Swietlicki, E., Zhou, J., Seidl, W., Becker, E., and O'Dowd, C.D.: Hygroscopic and CCN properties of aerosol particles in boreal forests, Tellus B, 53, 4, 359-379, doi:10.1034/j.1600-0889.2001.530404.x, 2001.

Hennigan, C. J., Sullivan, A. P., Fountoukis, C. I., Nenes, A., Hecobian, A., Vargas, O., Peltier, R. E., Case Hanks, A. T., Huey, L. G., Lefer, B. L., Russell, A. G., and Weber, R. J.: On the volatility and production mechanisms of newly formed nitrate and water soluble organic aerosol in Mexico City, Atmos. Chem. Phys., 8, 3761-3768, 2008,

http://www.atmos-chem-phys.net/8/3761/2008/.

Jayne, J. T., Leard, D. C., Zhang, X., Davidovits, P., Smith, K. A., Kolb, C. E., and Worsnop, D. R.: Development of an aerosol mass spectrometer for size and composition analysis of submicron particles, Aeros. Sci. Technol., 33, 49-70, 2000.

Jimenez, J.L. et al.: Evolution of organic aerosols in the atmosphere, Science, 326, 1525-1529, 2009.

Kalafut-Pettibone, A. J., Wang, J., Eichinger, W. E., Clarke, A., Vay, S. A., Blake, D. R., and Stanier, C. O.: Size-resolved aerosol factors and new particle formation/growth activity occurring in Mexico City during the MILAGRO 2006 Campaign, Atmos. Chem. Phys., 11, 8861-8881, doi:10.5194/acp-11-8861-2011, 2011.

Knutson, E. O. and K. T. Whitby: Aerosol classification by electric mobility, Apparatus, theory and applications, J. Aerosol Sci., 6, 443, 1975.

Lance, S.: Quantifying compositional impacts of ambient aerosol on cloud droplet formation, Published Doctoral Thesis, available at: http://etd.gatech.edu/theses/available/etd-11132007-175217/ unrestricted/lance_sara_m_200712_phd[1].pdf, 2007.
Lance, S., Medina, J., Smith, J. N., and Nenes, A.: Mapping the Operation of the DMT Continuous Flow CCN Counter, Aerosol Sci. Technol., 40, 242-254, doi:10.1080/02786820500543290, 2006.

Lathem, T. L. and Nenes, A.: Water vapor depletion in the DMT continuous flow CCN chamber: Effects on supersaturation and droplet growth, Aerosol Sci. Technol., 45, 604-615, doi:10.1080/02786826.2010.551146, 2011.

McMurry, P. H., Ghimire, A., Ahn, K.-H., Sakurai, H., Stolzenburg, M., and Smith, J. N.: Sampling nanoparticles for chemical analysis by low resolution electrical mobility classification, Environ. Sci. Technol., 43, 4653-4658, doi:10.1021/es8029335, 2009.

Moffet, R. C. and Prather, K. A.: In-situ measurements of the mixing state and optical properties of soot with implications for radiative forcing estimates, Proc. Natl. Acad. Sci. USA, 106, 11872-11877, 2009.

Molina, L. T., Madronich, S., Gaffney, J. S., Apel, E., de Foy, B., Fast, J., Ferrare, R., Herndon, S., Jimenez, J. L., Lamb, B., Osornio-Vargas, A. R., Russell, P., Schauer, J. J., Stevens, P. S., Volkamer, R., and Zavala, M.: An overview of the MILAGRO 2006 Campaign: Mexico City emissions and their transport and transformation, Atmos. Chem. Phys., 10, 8697-8760, doi:10.5194/acp-10-8697-2010, 2010.

Padró, L. T., Tkacik, D., Lathem, T., Hennigan, C. J., Sullivan, A. P., Weber, R. J., Huey, L. G., and Nenes, A.: Investigation of cloud condensation nuclei properties and droplet growth kinetics of the water soluble aerosol fraction in Mexico City, J. Geophys. Res., 115, D09204, 2010.

Petters, M. D. and Kreidenweis, S. M.: A single parameter representation of hygroscopic growth and cloud condensation nucleus activity, Atmos. Chem. Phys., 7, 1961-1971, doi:10.5194/acp-71961-2007, 2007.

Rader, D. J., and McMurry, P. H.: Application of the tandem differential mobility analyzer to studies of droplet growth or evaporation, J. Aerosol Sci., 17, 771-787, 1986.

Roberts, G. C., and Nenes, A.: A continuous-flow streamwise thermal-gradient $\mathrm{CCN}$ chamber for atmospheric measurements, Aerosol Sci. Technol., 39, 206-221, 2005.

Rose, D., Gunthe, S. S., Mikhailov, E., Frank, G. P., Dusek, U., Andreae, M. O., and Pöschl, U.: Calibration and measurement uncertainties of a continuous-flow cloud condensation nuclei counter (DMT-CCNC): CCN activation of ammonium sulfate and sodium chloride aerosol particles in theory and experiment, Atmos. Chem. Phys., 8, 1153-1179, doi:10.5194/acp-8-11532008, 2008.

Rose, D., Nowak, A., Achtert, P., Wiedensohler, A., Hu, M., Shao, M., Zhang, Y., Andreae, M. O., and Pöschl, U.: Cloud condensation nuclei in polluted air and biomass burning smoke near the mega-city Guangzhou, China - Part 1: Size-resolved measurements and implications for the modeling of aerosol particle hygroscopicity and CCN activity, Atmos. Chem. Phys., 10, 33653383, doi:10.5194/acp-10-3365-2010, 2010.

Rose, D., Gunthe, S. S., Su, H., Garland, R. M., Yang, H., Berghof, M., Cheng, Y. F., Wehner, B., Achtert, P., Nowak, A., Wiedensohler, A., Takegawa, N., Kondo, Y., Hu, M., Zhang, Y., Andreae, M. O., and Pöschl, U.: Cloud condensation nuclei in polluted air and biomass burning smoke near the mega-city Guangzhou, China - Part 2: Size-resolved aerosol chemical composition, diurnal cycles, and externally mixed weakly $\mathrm{CCN}$-active soot particles, Atmos. Chem. Phys., 11, 2817-2836, doi:10.5194/acp-11- 
2817-2011, 2011.

Salcedo, D., Onasch, T. B., Dzepina, K., Canagaratna, M. R., Zhang, Q., Huffman, J. A., DeCarlo, P. F., Jayne, J. T., Mortimer, P., Worsnop, D. R., Kolb, C. E., Johnson, K. S., Zuberi, B., Marr, L. C., Volkamer, R., Molina, L. T., Molina, M. J., Cardenas, B., Bernabé, R. M., Márquez, C., Gaffney, J. S., Marley, N. A., Laskin, A., Shutthanandan, V., Xie, Y., Brune, W., Lesher, R., Shirley, T., and Jimenez, J. L.: Characterization of ambient aerosols in Mexico City during the MCMA-2003 campaign with Aerosol Mass Spectrometry: results from the CENICA Supersite, Atmos. Chem. Phys., 6, 925-946, doi:10.5194/acp-6-925-2006, 2006.

Seinfeld, J. and Pandis, S.: Atmospheric Chemistry and Physics: from Air Pollution to Climate Change, John Wiley, New York, 1326 pp., 1998.

Sihto, S. L., Mikkila, J., Vanhanen, J., Ehn, M., Liao, L., Lehtipalo, K., Aalto, P. P., Duplissy, J., Petaja, T., Kerminen, V. M., Boy, M., and Kulmala, M.: Seasonal variation of CCN concentrations and aerosol activation properties in boreal forest, Atmos. Chem. Phys., 11, 13269-13285, doi:10.5194/acp-1113269-2011, 2011.

Smith, J. N., Dunn, M. J., VanReken, T. M., Iida, K., Stolzenburg, M. R., McMurry, P. H., and Huey, L. G.: Chemical composition of atmospheric nanoparticles formed from nucleation in Tecamac, Mexico: Evidence for an important role for organic species in nanoparticle growth, Geophys. Res. Lett., 35, L04808, doi:10.1029/2007GL032523, 2008.

Slowik, J. G., Stainken, K., Davidovits, P., Williams, L. R., Jayne, J. T., Kolb, C. E., Worsnop, R., Rudich, Y., DeCarlo, P. F., and Jimenez, J. L.: Particle morphology and density characterization by combined mobility and aerodynamic diameter measurements, Part 2: Application to combustion-generated soot aerosols as a function of fuel equivalence ratio, Aeros. Sci. Technol., 38, 1206-1222, 2004.
Stolzenburg, M. R., and McMurry, P. H.: TDMAfit user's manual, Particle Technology Laboratory, Department of Mechanical Engineering, Univeristy of Minnesota, Minneapolis, MN, Publication No. 653, 1988.

Su, H., Rose, D., Cheng, Y. F., Gunthe, S. S., Massling, A., Stock, M., Wiedensohler, A., Andreae, M. O., and Pöshcl, U.: Hygroscopicity distribution concept for measurement data analysis and modeling of aerosol particle mixing state with regard to hygroscopic growth and CCN activation, Atmos. Chem. Phys., 10, 7489-7503, doi:10.5194/acp-10-7489-2010, 2010.

Svenningsson, B. and Bilde, M.: Relaxed step functions for evaluation of CCN counter data on size-separated aerosol particles, J. Aerosol Sci., 39, 592-608, 10.1016/j.jaerosci.2008.03.004, 2008.

Velasco, E., Pressley, S., Grivicke, R., Allwine, E., Coons, T., Foster, W., Jobson, B. T., Westberg, H., Ramos, R., Hernández, F., Molina, L. T., and Lamb, B.: Eddy covariance flux measurements of pollutant gases in urban Mexico City, Atmos. Chem. Phys., 9, 7325-7342, doi:10.5194/acp-9-7325-2009, 2009.

Wang, J., Cubison, M. J., Aiken, A. C., Jimenez, J. L., and Collins, D. R.: T he importance of aerosol mixing state and size-resolved composition on CCN concentration and the variation of importance with atmospheric aging of aerosols, Atmos. Chem. Phys., 10, 7267-7283, doi:10.5194/acp-10-7267-2010, 2010. 